\title{
Deletion of Histone Methyltransferase G9a Suppresses Mutant Kras-driven Pancreatic Carcinogenesis
}

\author{
HIROYUKI KATO ${ }^{1}$, KEISUKE TATEISHI ${ }^{1}$, HIROAKI FUJIWARA ${ }^{1,2}$, HIDEAKI IJICHI ${ }^{1}$, KEISUKE YAMAMOTO ${ }^{1}$, \\ TAKUMA NAKATSUKA ${ }^{1}$, MIWAKO KAKIUCHI ${ }^{1}$, MAKOTO SANO $^{1,3}$, YOTARO KUDO ${ }^{1}$, \\ YOKU HAYAKAWA ${ }^{1}$, HAYATO NAKAGAWA ${ }^{1}$, YASUO TANAKA ${ }^{1}$, MOTOYUKI OTSUKA $^{1}$, \\ YOSHIHIRO HIRATA ${ }^{4}$, MAKOTO TACHIBANA ${ }^{5}$, YOICHI SHINKAI ${ }^{6}$ and KAZUHIKO KOIKE ${ }^{1}$ \\ ${ }^{1}$ Department of Gastroenterology, Graduate School of Medicine, The University of Tokyo, Tokyo, Japan; \\ ${ }^{2}$ Division of Gastroenterology, The Institute for Adult Diseases, Asahi Life Foundation, Tokyo, Japan; \\ ${ }^{3}$ Division of Medical Research Planning and Development, Nihon University School of Medicine, Tokyo, Japan; \\ ${ }^{4}$ Division of Clinical Genome Research, Advanced Clinical Research Center, \\ Institute of Medical Science, The University of Tokyo, Tokyo, Japan; \\ ${ }^{5}$ Laboratory of Epigenome Dynamics, Graduate School of Frontier Biosciences, Osaka University, Osaka, Japan; \\ ${ }^{6}$ Cellular Memory Laboratory, RIKEN Advanced Science Institute, Saitama, Japan
}

\begin{abstract}
Background/Aim: The entire mechanisms by which epigenetic modifiers contribute to the development of pancreatic cancer remain unknown. Although the histone methyltransferase $G 9 a$ is a promising target in human cancers, its role in pancreatic carcinogenesis has been understudied. The aim of the study was to examine the role of $G 9 a$ in pancreatic carcinogenesis by a gene-targeting mouse model. Materials and Methods: We established pancreasspecific G9aflox/flox mice and crossed them with PtflaCrel; Kras ${ }^{G 12 D /+}$ (KC) mice, which spontaneously develop pancreatic cancer. The phenotypes of the resulting $K C$ mice with G9a deletion were examined. We analyzed transcriptomic data by microarray and genome-wide chromatin accessibility by transposase-accessible chromatin using sequencing. We established pancreatic organoids from KC mice. Results: G9a deficiency impaired the progression of pancreatic intraepithelial neoplasia (PanIN) and prolonged the survival of KC mice. The number of phosphorylated Erk-positive cells and Dclk1-positive cells, which are reported to be essential for the progression of PanIN, were decreased by G9a deletion. UNC0638, an inhibitor of G9a, suppressed the growth of
\end{abstract}

This article is freely accessible online.

Correspondence to: Keisuke Tateishi, MD, Ph.D., Department of Gastroenterology, Graduate School of Medicine, The University of Tokyo, 7-3-1 Hongo, Bunkyo-ku, Tokyo 113-8655, Japan. Tel: +81 338155411, Fax: +81 358008812, e-mail: ktate-tky@umin.ac.jp

Key Words: Carcinogenesis, PanIN, PDAC, epigenetics, chromatin accessibility. organoids and increased global chromatin accessibility, especially around the regions including the protein phosphatase 2A genes. Conclusion: Thus, our study suggested the functional interaction of G9a, Dclkl and Mapk pathway in the Kras-driven pancreatic carcinogenesis. The inhibition of G9a may suppress the initiation of oncogenic Kras-driven pancreatic carcinogenesis.

Pancreatic cancer is the most common cause of cancerrelated mortality, with pancreatic ductal adenocarcinoma (PDAC) representing the most typical histological subtype. The global incidence of pancreatic cancer is predicted to be greater than 400,000; however, early diagnostic markers and therapeutic options still need to be developed (1). Genomic abnormalities, especially mutations or deletions in KRAS, TP53, SMAD4, and CDKN2A genes play essential roles in the development of PDAC. These mutations are already present in pancreatic intraepithelial neoplasms (PanINs), which are precursor lesions of PDAC (2), offering clues to the mechanism of pancreatic carcinogenesis (3).

To explain the evolution of pancreatic tumors, a gradual model has been proposed in which the independent accumulation of driver mutations and other oncogenic events accumulate during the long tumorigenic period (4). Additionally, a punctuated equilibrium model has been proposed in which pancreatic transformation is rapidly induced due to genetic instability (5). To date, many studies have elucidated the impact of these genetic events using genetically engineered mice harboring oncogenic $K R A S$ mutations $(6,7)$.

In addition to genomic events, the involvement of epigenomic factors in determining the malignant characteristics of pancreatic cancers has received much attention $(8,9)$. 
Although previous reports have documented the roles of various epigenetic modifiers using mutant Kras-driven mouse models (10-13), the significance of epigenetic factors in pancreatic tumor evolution remains obscure.

G9a is a specific methyltransferase responsible for $\mathrm{H} 3$ lysine 9 dimethylation ( $\mathrm{H} 3 \mathrm{~K} 9 \mathrm{me} 2)$, which is linked to transcriptional suppression. In addition, G9a plays a pivotal role in chromatin organization, for example, to adapt to the specific lineage commitment during normal developmental processes (14). In addition to its role in diverse biological processes in normal cells, the functions of G9a have been implicated in several types of cancers, including pancreatic cancer cells (15-17). However, its role in the initiation of pancreatic tumorigenesis remains to be elucidated.

For genomic or epigenomic analyses of tumor cells, the efficient isolation of cancer cells is important for avoiding the contamination of other stromal or immune cells. In particular, the abundant stromal components of PDAC are considered troublesome for various molecular studies. Organoids, which are recently developed culture models (18), are able to enrich cancer epithelial cells. In the research of PDAC, this model has been reported to be valuable for maintaining the original histological, biological, and molecular features of primary tumors (18-20).

In this report, we established a pancreas-specific $G 9 a$ knockout mouse model and examined the effects of this genetic manipulation on pancreatic carcinogenesis. Additionally, we examined the effects of $G 9 a$ deletion on the chromatin accessibility profile of organoids propagated from oncogenic Kras-harboring pancreatic cells.

\section{Materials and Methods}

Animals. All experiments were performed in accordance with protocols approved by the Animal Ethics Committee of the University of Tokyo, in accordance with the National Institutes of Health Guide for the Care and Use of Laboratory Animals (NIH Publication No. 8023, revised 1978). Floxed G9a (G9aflox/flox) mice were generated as previously described (21). Ptfla Crel+ mice and $L S L-K r a s^{G 12 D /+}$ mice have previously been described $(22,23)$. The mice were maintained in a temperature- and light-controlled facility and permitted ad libitum access to a regular chow diet and autoclaved water. All mice were backcrossed with the C57BL/6 strain, and both sexes were analyzed.

Histology and immunohistochemistry. Pancreatic tissues were fixed in $4 \%$ paraformaldehyde and embedded in paraffin. Tissue sections were stained with hematoxylin and eosin $(\mathrm{H} \& \mathrm{E})$ for pathological evaluation. The PanIN lesion grade was defined based on previously described criteria (24). For immunohistochemistry, mouse tissue slides were subjected to heat-induced antigen retrieval using $10 \mathrm{mM}$ citrate buffer ( $\mathrm{pH} 6.0)$, and incubated with the indicated primary antibodies overnight at $4^{\circ} \mathrm{C}$. Primary antibodies recognizing H3K9me2 (ab1220; Abcam, Cambridge, UK), G9a (PP-A8320A00; R\&D Systems, Minneapolis, MN, USA), Cpa1 (AF2765, R\&D
Systems), Krt19 (A-3; Santa Cruz Biotechnology, Dallas, TX, USA), Dclk1 (NBP1-96746; Novus Biologicals, Centennial, CO, USA), and phospho-Erk (9101; Cell Signaling Technology, Danvers, MA, USA) were used for immunohistochemical analysis. The sections were then incubated with biotinylated secondary antibodies and avidin-biotin-peroxidase (VECTASTAIN Elite ABC kit; Vector Laboratories, Burlingame, CA, USA), and were developed using diaminobenzidine as the chromogenic substrate. The slides were then briefly counterstained with hematoxylin. Negative control sections were not incubated with primary antibodies.

Quantitative reverse transcription PCR ( $q R T-P C R)$ analysis. Total RNA was extracted from tissues using an RNeasy Mini Kit (Qiagen, Hilden, Germany) and quantified using a NanoDrop spectrophotometer. Total RNA $(1 \mu \mathrm{g})$ was reverse transcribed using the ImProm-II Reverse Transcription System (Promega, Madison, WI, USA). qRT-PCR analysis was performed using the StepOnePlus Real-Time PCR System (Applied Biosystems, Foster City, CA, USA) according to the manufacturer's instructions. The test transcript levels were internally normalized against $A c t b$ transcript levels. The primers used for qRT-PCR were as follows: Dclkl forward, 5'-GCTGGGGACTTGACACATTT-3'; Dclk1 reverse, 5'-CAAGGGCAGACTCTCCAAAG-3'; Actb forward, 5'-CTGGA ACGGTGAAGGTGACA-3'; Actb reverse, 5'- AAGGGACT TCCTGTAACAACGCA-3'.

Microarray analysis. Microarray analyses were performed using the GeneChip Mouse Gene 2.0 ST Assay according to the manufacturer's protocol (Affymetrix, Santa Clara, CA, USA). Briefly, total RNA was extracted from murine pancreata obtained from PtflaCre/+; Kras ${ }^{G 12 D /+}(\mathrm{KC})$ and PtflaCrel+ ; Kras ${ }^{G 12 D /+}$; $G 9 a^{\text {flox/flox }}(G G K C)$ mice approximately 12 months after birth $(\mathrm{n}=2$ each). RNA quality was determined using the Agilent 2100 Bioanalyzer (Agilent, Santa Clara, CA, USA). Fragmented, labeled cDNA was constructed using the GeneChip WT PLUS Reagent Kit and hybridized in a GeneChip Hybridization Oven 645 at $45^{\circ} \mathrm{C}$ for $16 \mathrm{~h}$. Array scanning was performed using a GeneChip Scanner $30007 \mathrm{G}$ instrument. These experiments and the associated data processing were outsourced to Filgen Biosciences (Nagoya, Japan). Data analysis complied with the Minimum Information About Microarray Experiments standard. Prior to performing data analysis, chrX,Y and non-annotated probes were excluded, resulting in 19,166 probes included in the analysis. The probe design files and microarray data were submitted to the National Center for Biotechnology Information Gene Expression Omnibus database, with the accession number GSE149093.

Organoid culture. Organoids were established from murine pancreata using published protocols (18). Resected mouse pancreata were minced under sterile conditions and digested using $1 \mathrm{mg} / \mathrm{ml}$ collagenase type IV (Invitrogen, Carlsbad, CA, USA) in PBS for 10 $\min$. The suspension was filtered through a cell strainer $(100 \mu \mathrm{m})$ and centrifuged to sediment. The resulting pellet was mixed with Matrigel (BD Biosciences, Franklin Lakes, NJ, USA) and the tissue was cultured in vitro, as previously described (18), in AdDMEM/F12 medium (Invitrogen) supplemented with B27 (Invitrogen), $1.25 \mu \mathrm{M} \mathrm{N}$-acetylcysteine (Wako, Osaka, Japan), 50 ng/ml EGF (Wako), 100 ng/ml Fgf10 (Wako), 10\% Wnt3aconditioned medium, 10\% RSPO1-conditioned medium, $10 \mathrm{nM}$ gastrin (Sigma-Aldrich), and $10 \mathrm{mM}$ nicotinamide (Sigma-Aldrich). Additionally, for 4 days after seeding, the cells were supplemented 
with $100 \mathrm{ng} / \mathrm{ml}$ Noggin (PeproTech, Cranbury, NJ, USA). For transposase-accessible chromatin using sequencing (ATAC-seq) experiments, the organoids were treated with DMSO or UNC0638 (Selleck Chemicals, Houston, TX, USA) for $24 \mathrm{~h}$.

ATAC-seq. ATAC-seq experiments were performed on 50,000 cells from the organoid samples, following published protocols (25). ATAC-seq reads were processed as follows. Sequence reads were trimmed and aligned to the mouse genome (mm10) using BWA (26). PCR duplicates were removed using Picard's MarkDuplicates tool, and peaks were called using MACS2, with the parameter $\mathrm{q}=0.05$ (27). All peaks were merged to obtain consensus peak sets. Reads for each peak were extracted using featureCounts (28) and were normalized by computing $\log 2 \mathrm{CPM}$ using edgeR, before being used for downstream analysis (29). The peaks were annotated to the nearby genes by GREAT software (30). These data have been submitted to the National Center for Biotechnology Information Gene Expression Omnibus database, with the accession number GSE151434.

Statistical analysis. The data are presented as means \pm standard errors of the mean. Statistical analyses were performed using a two-tailed Student's $t$-test.

\section{Results}

G9a deficiency attenuated PanIN progression in KC mice. $K C$ mouse pancreata spontaneously developed acinar ductal metaplasia (ADM), murine PanINs (mPanINs), and invasive tumors (6). To assess the role of G9a in pancreatic tumorigenesis, we analyzed the phenotypic effects of $G 9 a$ deficiency in $K C$ mice. The loss of G9a expression was confirmed in the $G G K C$ mouse pancreas. The pancreatic tissues of $K C$ mice developed ADM and various stages of mPanINs several months after birth, while the mPanINs were less prominent in the $G G K C$ mouse pancreas (Figure 1A, left). Alcian blue staining confirmed a limited distribution of mPanIN lesions with mucin production in the $G G K C$ compared with $K C$ mice (Figure 1A, middle). Moreover, Masson's trichrome staining suggested more fibrotic changes in the $K C$ mouse pancreas (Figure 1A, right). To estimate the degree of mPanIN progression, we counted the number of respective grades of mPanINs. At 2 months after birth, the development of mPanIN1 was similar in both groups (Figure 1B). In contrast, up to $\sim 1$ year of age, the number of PanIN2 and PanIN3 lesions gradually increased in the $K C$ mouse pancreas, but they were rarely found in $G G K C$ mice (Figure 1B). $K C$ mice occasionally developed pancreatic cancer (6), but GGKC mice did not (Figure 1C). Finally, the median survival time of the GGKC mice was significantly longer than that of the $K C$ mice [627 days $(\mathrm{n}=18)$ vs. 419 days $(\mathrm{n}=17),{ }^{*} p<0.0001$, Figure 1D]. No association with sex was observed in these results. Taken together, these data suggested that G9a played an important role in pancreatic oncogenesis in the presence of Kras mutations.
$G 9$ a deletion retained the molecular transition in $A D M$. The induction of ADM, which involves the degranulation of acinar cells and the emergence of cuboidal to columnar ductlike structures, is often observed prior to mPanIN formation in $K C$ mice. G9a was expressed in the ADM lesions in $K C$ mice, but not in GGKC mice (Figure 2A). Consistent with the ability of G9a to introduce di-methylation of H3K9 (21), $\mathrm{H} 3 \mathrm{~K} 9 \mathrm{me} 2$ was absent in the ADM lesions of GGKC mice (Figure 2B). To assess the metaplastic status of ADM lesions in $G G K C$ mice, we analyzed the expression of the acinar and ductal lineage markers, carboxypeptidase A1 (Cpa1) and cytokeratin 19 (Krt19), respectively, in serially sectioned specimens. Immunohistochemical analysis of these proteins indicated more ADM lesions in the $K C$ pancreas than in the $G G K C$ pancreas (Figure 2C and D). Cells positive for Cpa1 or Krt19 existed in a mutually exclusive pattern, coinciding with the cell lineages in the ADM lesions of $K C$ mice (Figure 2E and F, upper). This mutually exclusive expression of Cpa1 and Krt19 was conserved in the ADM lesions of GGKC mice (Figure $2 \mathrm{E}$ and $\mathrm{F}$, lower), indicating that the emergence of ADM was less frequent, but still occurred, in the GGKC pancreas (Figure 1B). Therefore, we suspected that G9a may be more critical in the progression of mPanIN than the development of ADM (Figure 1B).

G9a deficiency reduced the number of Dclk1-positive tuftlike cells and Erk phosphorylation in mPanIN lesions. To identify the genes responsible for the impaired progression of mPanIN in the $G G K C$ pancreas, gene expression profiles were analyzed in whole pancreata of $K C$ and $G G K C$ mice. Among the 19,166 probes analyzed, 147 genes were found to be significantly up-regulated and 178 genes were downregulated in the pancreata of $G G K C$ mice compared to the pancreata of $K C$ mice. Genes encoding pancreatic enzymes were significantly enriched in the $G G K C$ mouse pancreas (Figure 3A), concurrent with the preservation of acinar cells in these mice (Figure 1). Down-regulated genes included epithelial genes, such as Krt20 (Figure 3A), which was likely due to fewer metaplastic duct cells. Furthermore, we found decreased expression levels of doublecortin-like kinase-1 (Dclk1) in GGKC mice (Figure 3A). Dclk1 was reported to mark a population of pancreatic cancer-initiating cells (31, 32). In addition, Dclk1 was suggested to be a marker of normal pancreatic stem/progenitors $(32,33)$. The downregulation of $D c l k l$ in $G G K C$ mice was confirmed in the validation cohorts (Figure 3B). As previously reported, Dclk1-positive cells presented the typical morphological features of intestinal tuft cells, with a narrow apical side and a wide basal surface in $K C$ mice (asterisk in Figure $3 \mathrm{C}$, upper right) $(31,34)$. However, the number of Dclk1-positive cells was clearly lower in the GGKC mouse pancreas $(40.0 \%$ vs. $11.9 \%,{ }^{*} p<0.01$, Figure $3 \mathrm{C}$ and $\left.3 \mathrm{D}\right)$ and, if present, they did not always show the classic tuft cell morphology (Figure 
A
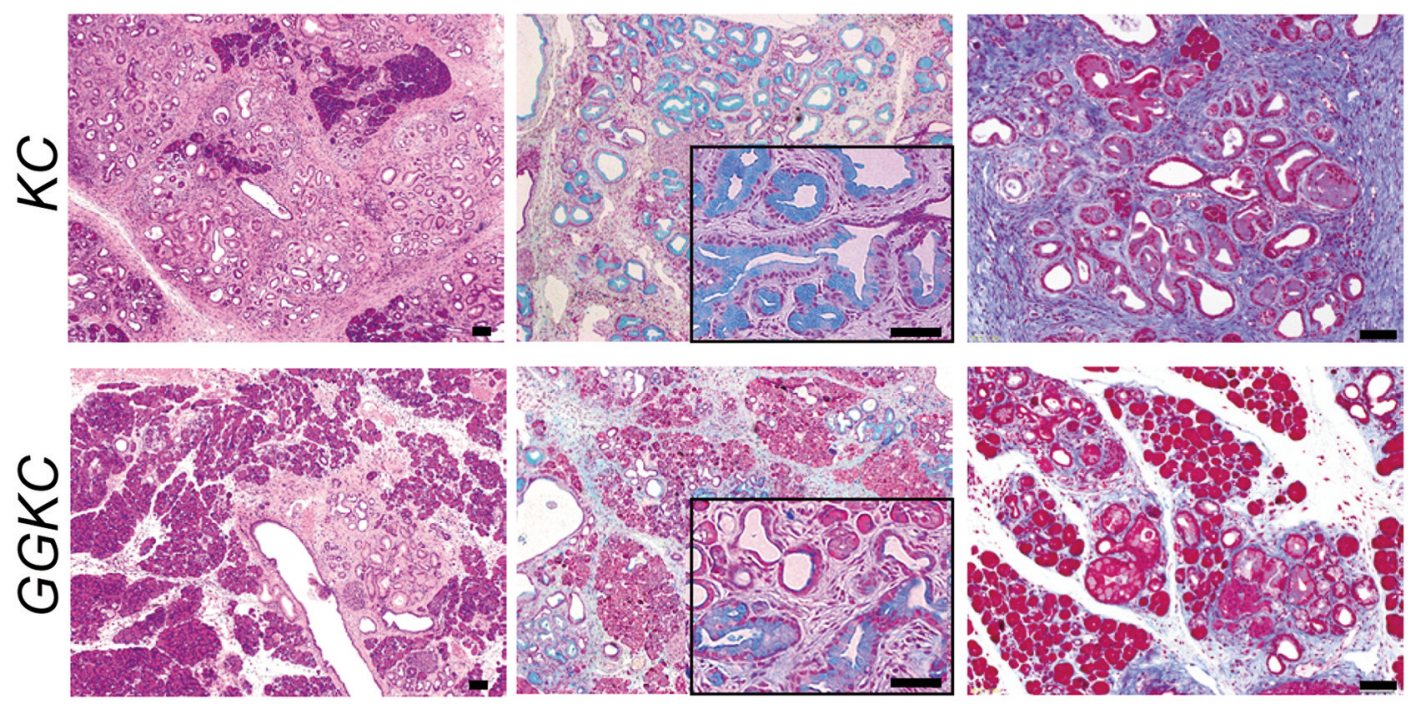

B
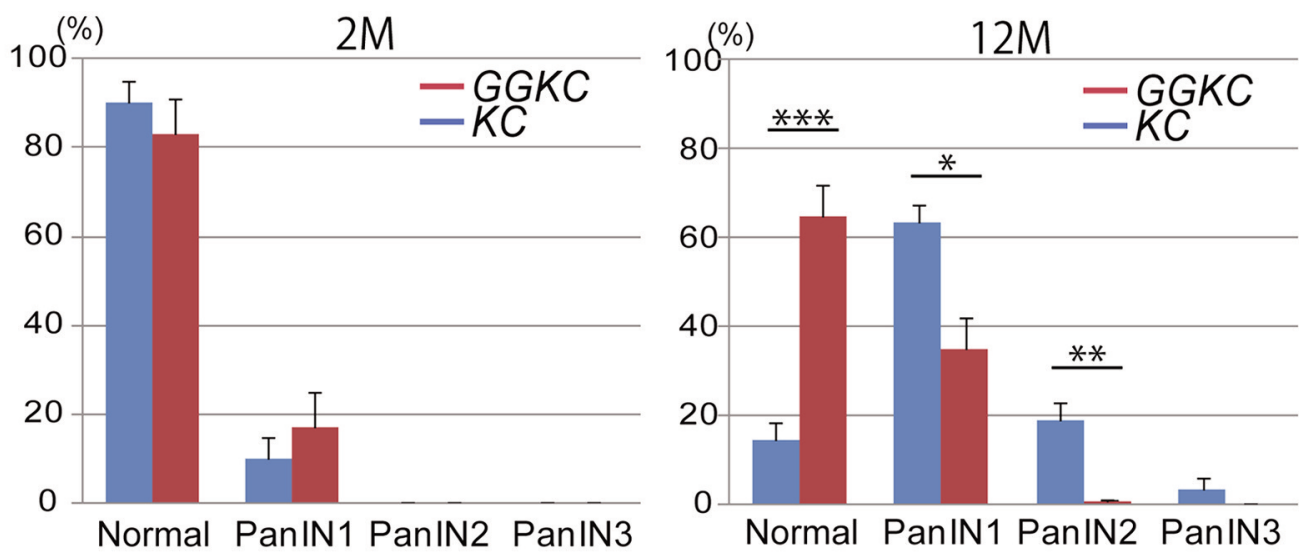

C
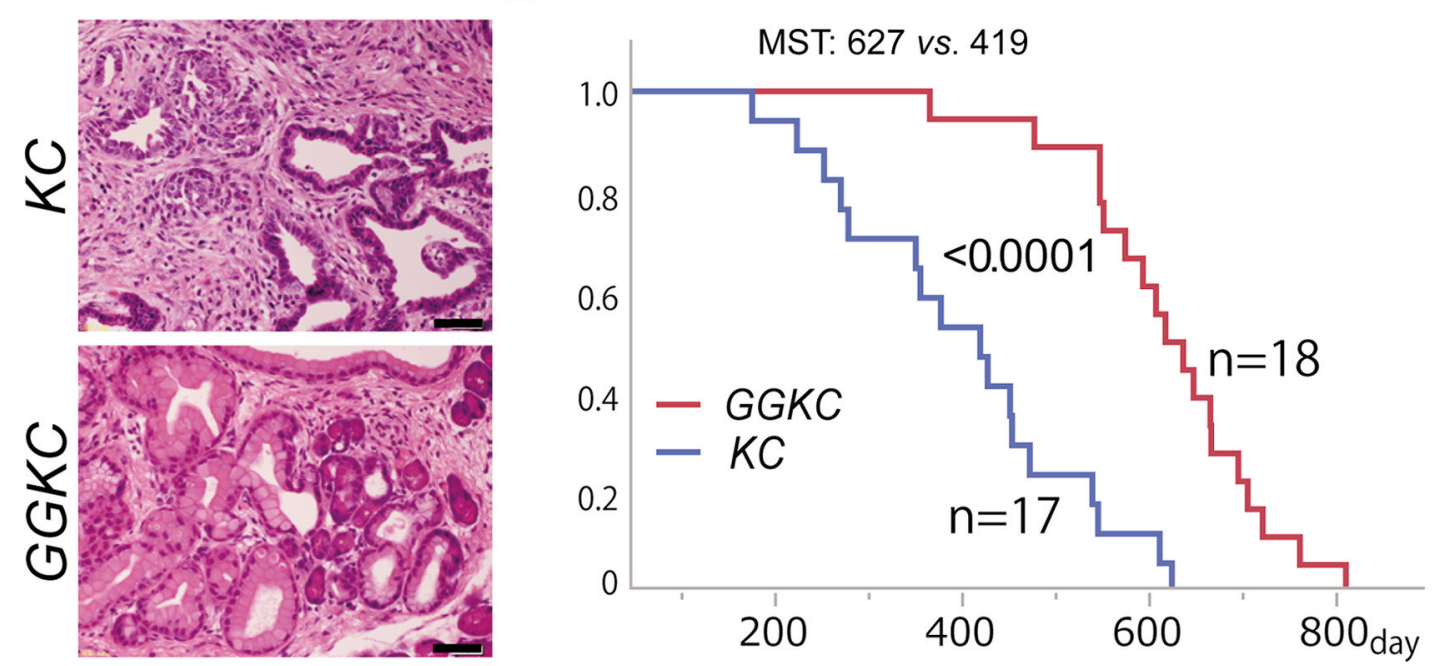

Figure 1. Depletion of G9a impaired the progression of PanIN in P48-Cre; KrasG12D (KC) mice. (A) Representative images of pancreatic tissue from the KC and GGKC mice. Left: H\&E staining at 6 months. Center: Alcian blue staining at 11 months. Right: Masson's trichrome staining at 11 months. Scale bars: $50 \mu \mathrm{m}$. (B) Percentages of normal and neoplastic ducts in mice with an average age of 2 months ( $n=8$ lesions from 4 mice each) and 12 months ( $n=10$ lesions from 5 mice each). ${ }^{*} p<0.01,{ }^{*} p<0.001$, ${ }^{* * *} p<0.0001$. (C) Representative images of pancreatic tumors in KC mice and PanIN lesions in the pancreata of GGKC mice at 13 months. (D) Survival duration of KC and GGKC mice. $p<0.0001$. MST: median survival time. 
3C, lower right). Given the reported critical function of Dclk1-positive cells in the expansion of PanINs $(32,35)$, we suspected that the absence of these cells led to the impaired progression of mPanINs in GGKC mice. Dclk1 has been reported to function as an effector of the mitogen-activated protein kinase (Mapk) pathway in the presence of Kras mutations in pancreatic carcinogenesis (32). The Mapk pathway mediates the de-differentiation of acinar cells into duct-like cells and the subsequent initiation of tumorigenesis $(36,37)$. Therefore, we next examined the activation status of Erk in $K C$ and $G G K C$ mouse pancreata. Erk phosphorylation levels were clearly decreased in $G G K C$ mice compared with $K C$ mice $\left(38.3 \%\right.$ vs. $12.8 \%,{ }^{*} p<0.05$, Figure $3 \mathrm{E}$ and F). Of note, the Dclkl-deficient $\mathrm{Kras}^{\mathrm{Gl}} \mathrm{CD} /+$ mice demonstrated a phenotype similar to that of $G G K C$ mice, namely, suppressed activation of the Mapk pathway and impaired development of high-grade PanIN lesions (32). Taken together, these data indicated that the impaired activation of Erk may contribute to the decreased progression of mPanINs in GGKC mice.

G9a was essential for the viability of mutant Kras-harboring pancreatic organoids. To confirm the in vivo findings, we next aimed to culture pancreatic organoids established from $K C$ and $G G K C$ mouse pancreata. The pancreatic organoids from $K C$ mice continuously grew, as previously reported (18); however, those from GGKC mice did not survive in the culture (Figure $4 \mathrm{~A})$. Additionally, when the pancreatic organoids from $K C$ mice were treated with UNC0638, a G9a chemical inhibitor, the growth of the organoids was clearly inhibited (Figure 4B). These data indicated that G9a was essential for the survival of mutant Kras-harboring pancreatic cells.

Inhibition of G9a affected chromatin accessibility in mutant Kras-harboring pancreatic cells. Finally, we analyzed the epigenetic status of pancreatic organoid cells. Given the function of G9a in regulating chromatin organization (38), chromatin accessibility in pancreatic organoid cells was examined using an ATAC-seq assay (25). Treatment with UNC0638 induced a greater number of open chromatin lesions in the organoids from $K C$ mice $(K C v s$. $\mathrm{KC}+\mathrm{UNC} 0638, p<10^{-300}$, Figure 5A). Notably, the open chromatin lesions induced by UNC0638 treatment were enriched in genes of the protein phosphatase 2A (PP2A)- and Mapk-related categories (Figure 5B). PP2A regulates various oncogenic signals, including Mapk (39), and has been reported to inhibit Kras-driven lung tumor growth (40). The higher chromatin accessibility around PP2A-related genes was found in the UNC0638-treated organoids (Figure 5C and D). Despite the technical difficulties in validating the altered chromatin accessibility in the pancreas in vivo, it is possible that altered chromatin status may be involved in the phenotype observed in the GGKC mouse pancreas. In
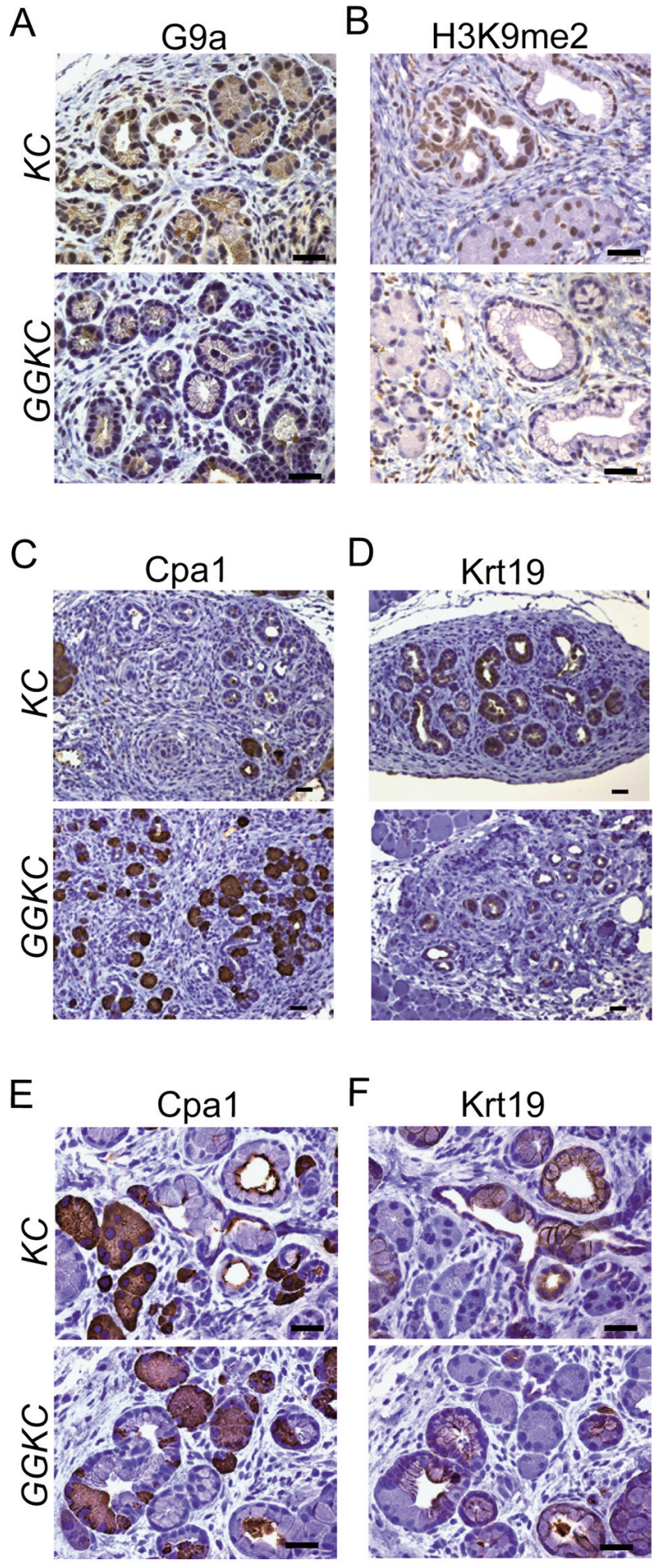

Figure 2. Spared acinar ductal transition shown by marker expression in the GGKC mouse pancreas. Representative staining images for $G 9 a$ (A) and H3K9me2 (B) in pancreatic tissues obtained from KC or GGKC mice. Scale bars: $50 \mu \mathrm{m}$. (C-F) Representative staining images for Cpal $(C, E)$ and $\operatorname{Krt19}(D, F)$ in ADM tissues obtained from KC and GGKC mice. Scale bars: $50 \mu \mathrm{m}$. 

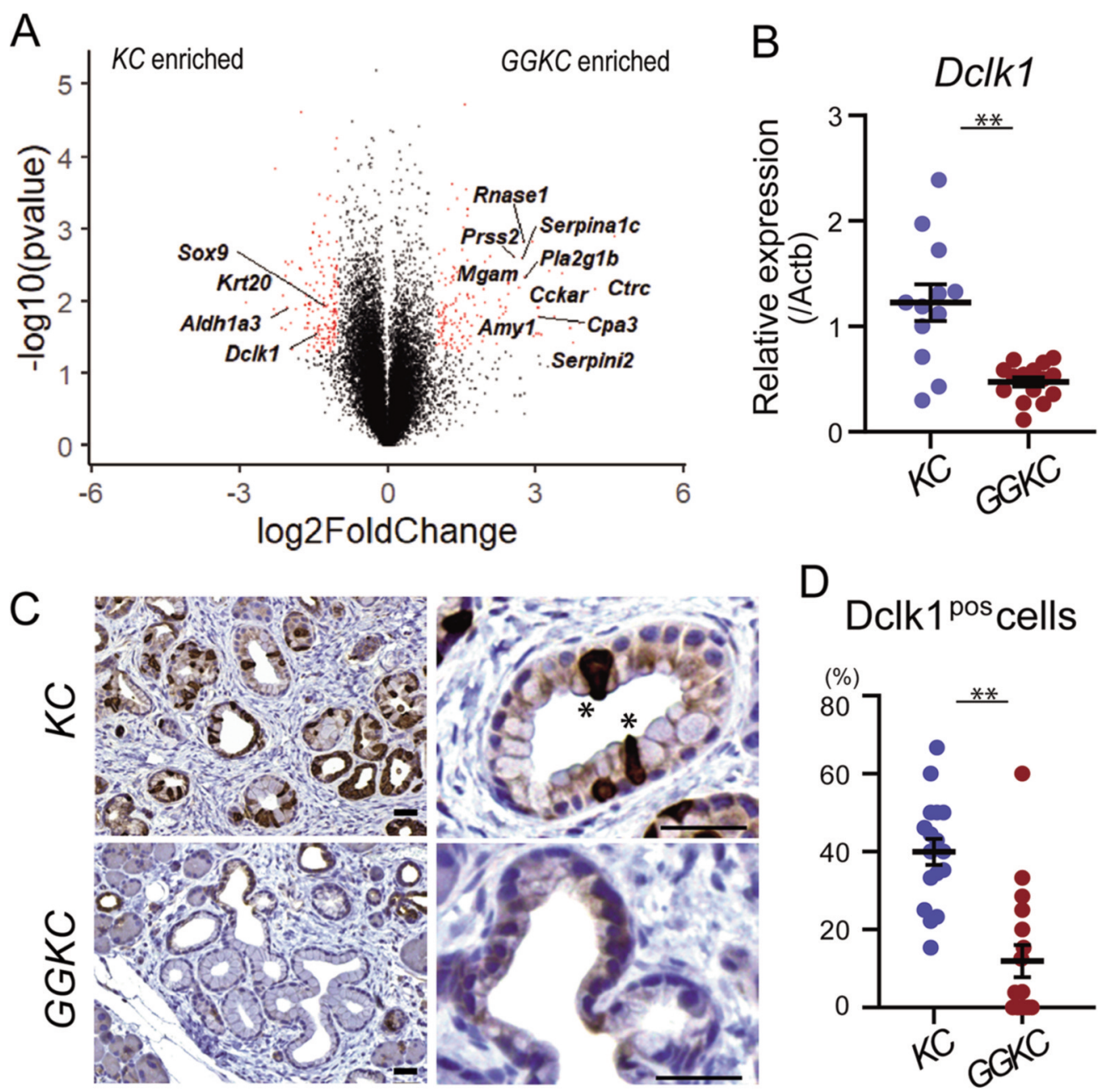

\section{Dclk1 ${ }^{\text {pos }}$ cells}
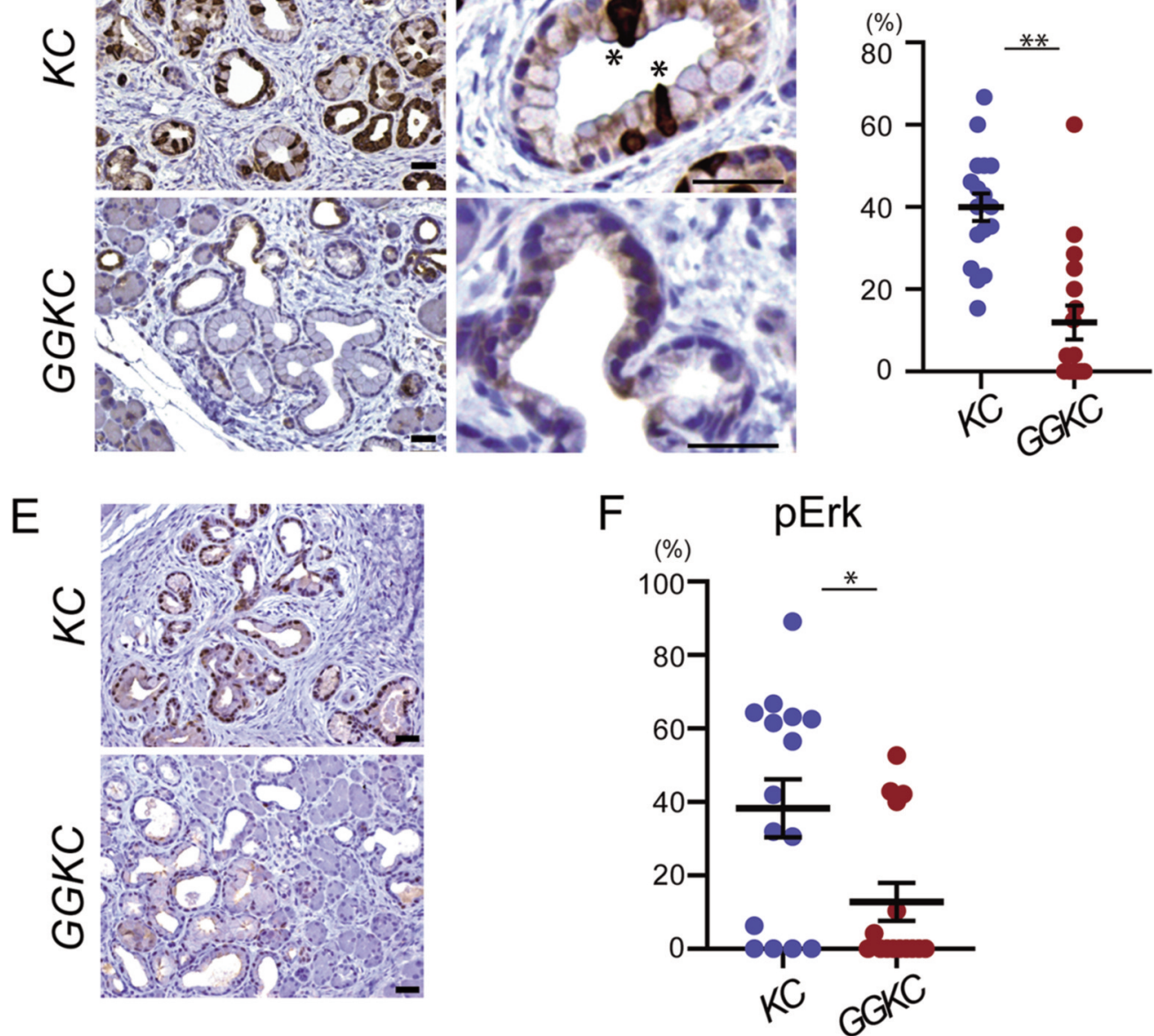

Figure 3. G9a deficiency reduced the number of Dclk1-positive cells and inhibited Erk phosphorylation in mPanIN lesions. (A) Comparison of gene expression between $K C$ and GGKC pancreata. Red dots denote differentially expressed genes $(p<0.05, \log 2 F C<-1,>1)$. (B) qRT-PCR analysis of relative Dclk1 expression in $K C$ and GGKC mice. ${ }^{* *} p<0.01$. (C) Dclk1 staining of the pancreata of KC and GGKC mice. Asterisk indicates the tuft-like structure. Scale bars: 50 um (D) Ratio of Dclk1-positive cells in mPanIN lesions $(n=17$ lesions from 2 mice each). ** $p<0.01$. Scale bars: $50 \mu \mathrm{m}$. (E) Staining of phospho-Erk in the pancreata of KC and GGKC mice. Scale bars: $50 \mu \mathrm{m}$. (F) Ratio of phospho-Erk-positive cells in mPanIN lesions ( $n=15$ lesions from 3 mice each). * $p<0.05$. 
conclusion, G9a is an epigenetic modifier essential for the expansion of pancreatic cells harboring oncogenic KRAS mutations.

\section{Discussion}

In this study, we established a pancreas-specific $69 a$ knockout mouse model and analyzed the effects on mutantKras-driven pancreatic tumorigenesis using this model. While the role of G9a in pancreatic cancer cells has previously been reported (15-17), the effects on chromatin accessibility by G9a inhibition were not analyzed. This study demonstrated the significance of G9a in the initiation of pancreatic cancer development in vivo.

In the $G G K C$ mouse pancreas, low-grade mPanINs and ADM lesions were fewer in number, but still observed. In contrast, high-grade mPanINs were barely detected (Figures 1 and 2), implying the role of G9a in the malignant transition of low-grade mPanIN lesions. Expression analysis to address the genes responsible for the impaired mPanIN progression in the $G G K C$ mouse pancreas revealed decreased expression levels of Dclk1 (Figure 3). Of note, the pancreas-specific Dclkl-knockout mouse demonstrates delayed progression of mPanIN lesions (32), similar to the situation seen in GGKC mice. Therefore, we considered that the decrease in the number of Dclk1-positive cells may be related to the phenotype of the GGKC mouse pancreas. However, the exact mechanism linking the loss of G9a to the number of Dclk1positive cells remains unclear.

The activation of Mapk downstream of Kras leads to multiple cellular effects including transcription, cell cycle regulation and survival (41). The inhibition of Mapk pathway resulted in regression of mPanIN regions induced by oncogenic Kras (36), indicating the pivotal role in the maintenance of mPanIN. In addition, Mapk mediates the dedifferentiation of oncogenic Kras harboring acinar cells to duct-like cells. The mechanism is considered to be mediated by the altered expression of key transcription factors including Mist1, Sox9, Hes1 and Pdx1 (36, 37). Phosphorylation of Erk indicates the activation of the Mapk pathway. Functional relationships between G9a and ERK have previously been reported in other models $(42,43)$. Although the relationship between G9a and ERK is unknown in pancreatic cells, GGKC mice showed a decreased number of phospho-Erk-positive PanIN cells (Figure 4). Dclk1 has been reported to be a critical factor for Mapk activation in pancreatic cancer cells, through direct binding to Kras protein (32). In addition, Dclk1-positive cells have clonogenic potential, sustaining the growth of pancreatic cancer organoids $(31,32)$. Taken together with our data, these findings indicate that G9a may be related to Mapk activation and the clonogenic ability of Dclk1-positive cells in the pancreata of $K C$ mice.
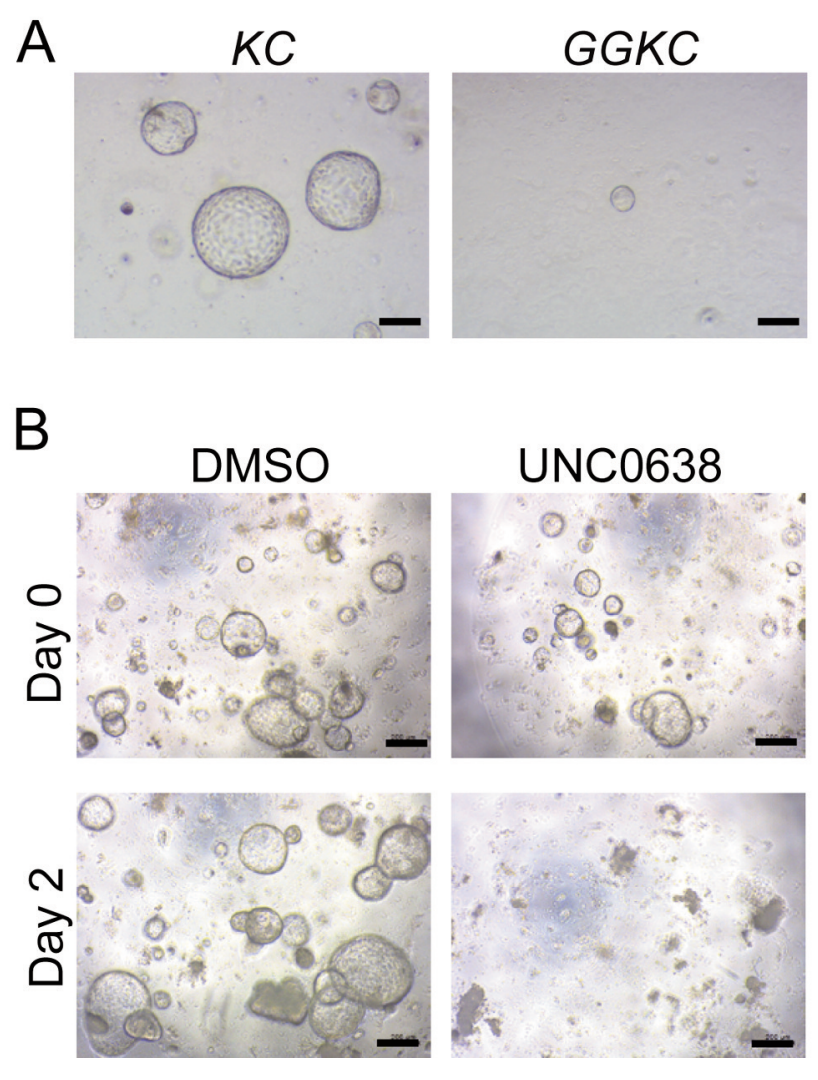

Figure 4. Treatment with UNC0638 affected the growth of pancreatic organoids from KC mice. (A) Representative images of organoids established from KC and GGKC mouse pancreata. Scale bar: $200 \mu \mathrm{m} .(B)$ Representative images of organoids derived from $\mathrm{KC}$ mice at day 2 after treatment with DMSO or $10 \mu M$ UNC0638 for $24 \mathrm{~h}$. Scale bar: $200 \mu \mathrm{m}$.

Altered chromatin accessibility due to G9a inhibition has been shown in a previous study $(38,44)$. Consistent with these findings, G9a deletion affected the global level of chromatin accessibility in pancreatic organoids derived from $K C$ mice (Figure 5A). In addition, PP2A-related genes, which are negative regulators of the Mapk pathway, were identified as the most affected gene category (Figure 5B). Considering that the functional relationship of G9a and PP2A phosphatase activity has been previously reported (45), PP2A may be involved in the impaired activation of Mapk in the $G G K C$ mouse pancreas. However, in general, the extent to which the altered chromatin structure is directly linked to the biological outcome remains obscure.

H3K9 dimethylation status can be demethylated by a histone demethylase KDM3A/JHDM2A/JMJD1A (46). A recent study showed that $K D M 3 A$ knockdown suppresses DCLK1 expression in human pancreatic cancer cell (47). While our data contradicted these previous findings, there was a clear difference in the model used in the two studies. Our study focused on the initiation of pancreatic 
A

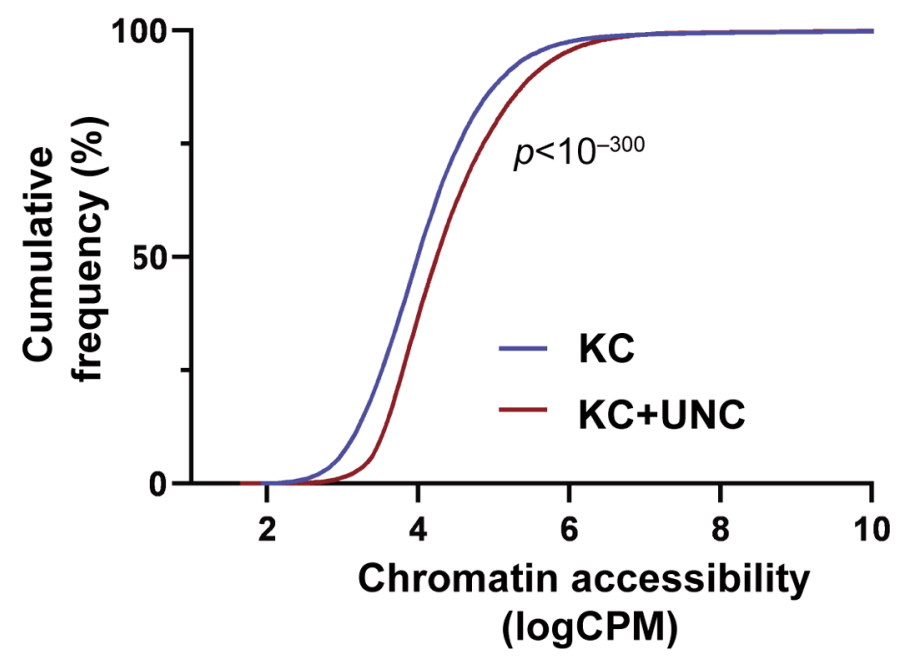

B

GO molecular function $\quad-\log 10$ (Binomial $p$-value)

PP2A regulator activity

CREB binding

MAP kinase binding

GDP binding

C

\# GREAT version 3.0.0 Species assembly: mm10 Association

\begin{tabular}{llllll} 
Ensa & Igbp1 & Ppp2r2b & Ppp2r2c & Ppp2r2d & Ppp2r3a \\
Ppp2r4 & Ppp2r5a & Ppp2r5c & Ppp2r5d & Ppp2r5e & \\
\hline
\end{tabular}
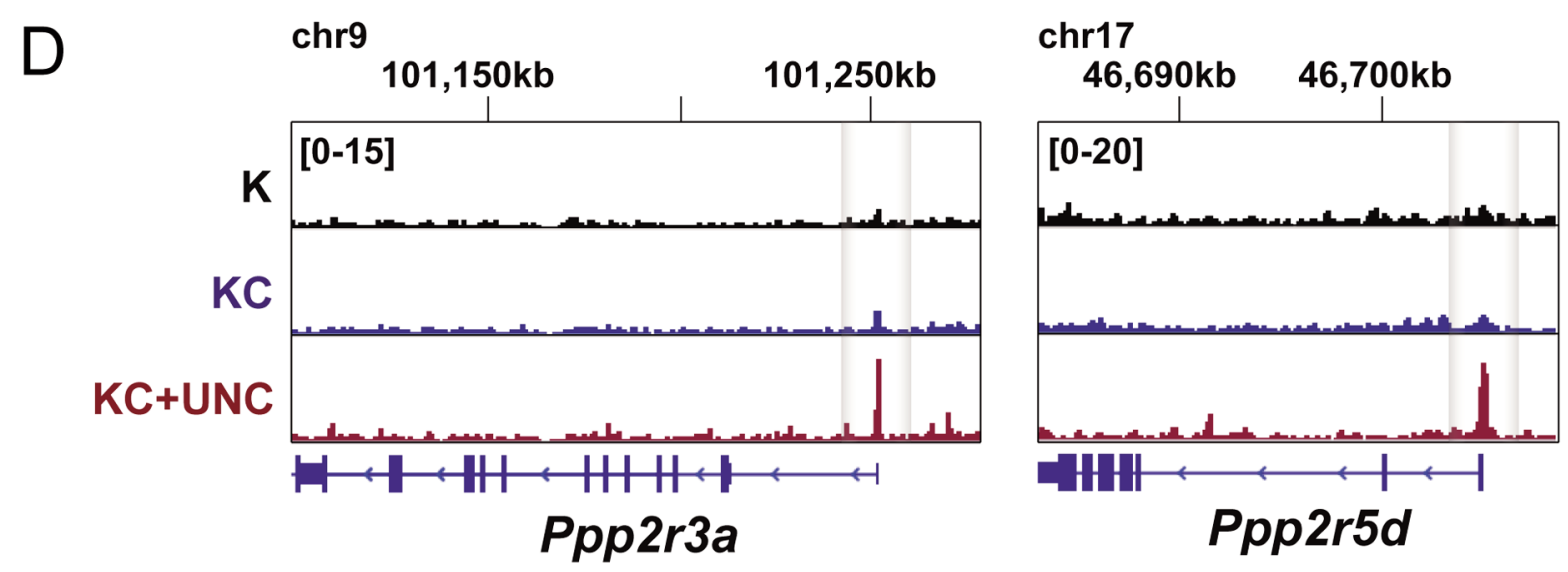

Figure 5. G9a affected chromatin accessibility in pancreatic organoids derived from KC mice. (A) Histogram of global chromatin accessibility in $K C$ and KC+UNC0638 organoids. p <10-300. (B) Gene ontology molecular function categories of ATAC-enriched peaks in KC $+U N C 0638$ organoids, compared to KC organoids. (C) PP2A-related genes were enriched in ATAC peaks in KC+UNC0638 organoids, as analyzed using GREAT software. (D) Representative ATAC tracks at the Ppp2r3a and Ppp2r5d loci in normal (K), KC, and KC+UNCO638 organoids. Grayed box in each locus denotes the differential ATAC peaks. 
tumorigenesis in an in vivo mouse model, whereas, the previous study analyzed established human pancreatic cancer cells. Indeed, because the tuft-like Dclk1-positive cells observed in $K C$ mice are rarely seen in established pancreatic cancer tissues $(32,35)$, the Dclk1-positive cells analyzed in the two studies may be distinct cell populations.

In summary, our data suggested a possible effect of G9a inhibition on pancreatic carcinogenesis. To date, some G9a inhibitors have been developed as potential anti-cancer agents. However, a recent study indicated that long-term G9a inhibitor administration induced selection for aggressive Trp53-mutant tumors (38). That study suggested the possibility that the outcomes of inhibiting G9a may be affected by the features or stage of the tumor, such as Trp53 mutation status. The efficacy of epigenetic therapy may depend on the genomic profile, in a manner similar to the current molecular targeting agents.

\section{Conflicts of Interest}

The Authors declare that they have no competing interests.

\section{Authors' Contributions}

Conception and design: KT, HK. Development of methodology: KT, HK, KY, TN, YK, and HI. Acquisition of data and management of animal samples: KT, HK, and HF. Resources: MT, YS. Writing and review: MK, MS, YH, HN, YT, MO, YH, and KK. Final approval of article: All Authors.

\section{Acknowledgements}

This study was partially supported by Grants from JSPS KAKENHI (Grant Number 23591009, 18K07962) and a grant from the International Joint Usage/Research Center, the Institute of Medical Science, the University of Tokyo. We thank Mitsuko Tsubouchi and Sayaka Ito for their technical assistance.

\section{References}

1 Neoptolemos JP, Kleeff J, Michl P, Costello E, Greenhalf W and Palmer DH: Therapeutic developments in pancreatic cancer: current and future perspectives. Nat Rev Gastroenterol Hepatol 15(6): 333-348, 2018. PMID: 29717230. DOI: 10.1038/s41575018-0005-x

2 Basturk O, Hong SM, Wood LD, Adsay NV, Albores-Saavedra J, Biankin AV, Brosens LA, Fukushima N, Goggins M, Hruban RH, Kato Y, Klimstra DS, Klöppel G, Krasinskas A, Longnecker DS, Matthaei H, Offerhaus GJ, Shimizu M, Takaori K, Terris B, Yachida S, Esposito I and Furukawa T: A revised classification system and recommendations from the Baltimore consensus meeting for neoplastic precursor lesions in the pancreas. Am J Surg Pathol 39(12): 1730-1741, 2015. PMID: 26559377. DOI: 10.1097/PAS.0000000000000533

3 Kanda M, Matthaei H, Wu J, Hong SM, Yu J, Borges M, Hruban RH, Maitra A, Kinzler K, Vogelstein B and Goggins M: Presence of somatic mutations in most early-stage pancreatic intraepithelial neoplasia. Gastroenterology 142(4): 730-733, 2012. PMID: 22226782. DOI: 10.1053/j.gastro.2011.12.042

4 Yachida S, Jones S, Bozic I, Antal T, Leary R, Fu B, Kamiyama M, Hruban RH, Eshleman JR, Nowak MA, Velculescu VE, Kinzler KW, Vogelstein B and Iacobuzio-Donahue CA: Distant metastasis occurs late during the genetic evolution of pancreatic cancer. Nature 467(7319): 1114-1117, 2010. PMID: 20981102. DOI: $10.1038 /$ nature09515

5 Notta F, Chan-Seng-Yue M, Lemire M, Li Y, Wilson GW, Connor AA, Denroche RE, Liang SB, Brown AM, Kim JC, Wang T, Simpson JT, Beck T, Borgida A, Buchner N, Chadwick D, HafeziBakhtiari S, Dick JE, Heisler L, Hollingsworth MA, Ibrahimov E, Jang GH, Johns J, Jorgensen LG, Law C, Ludkovski O, Lungu I, Ng K, Pasternack D, Petersen GM, Shlush LI, Timms L, Tsao MS, Wilson JM, Yung CK, Zogopoulos G, Bartlett JM, Alexandrov LB, Real FX, Cleary SP, Roehrl MH, McPherson JD, Stein LD, Hudson TJ, Campbell PJ and Gallinger S: A renewed model of pancreatic cancer evolution based on genomic rearrangement patterns. Nature 538(7625): 378-382, 2016. PMID: 27732578. DOI: $10.1038 /$ nature 19823

6 Hingorani SR, Petricoin EF, Maitra A, Rajapakse V, King C, Jacobetz MA, Ross S, Conrads TP, Veenstra TD, Hitt BA, Kawaguchi Y, Johann D, Liotta LA, Crawford HC, Putt ME, Jacks T, Wright CV, Hruban RH, Lowy AM and Tuveson DA: Preinvasive and invasive ductal pancreatic cancer and its early detection in the mouse. Cancer Cell 4(6): 437-450, 2003. PMID: 14706336. DOI: 10.1016/s1535-6108(03)00309-x

7 Hruban RH, Adsay NV, Albores-Saavedra J, Anver MR, Biankin AV, Boivin GP, Furth EE, Furukawa T, Klein A, Klimstra DS, Kloppel G, Lauwers GY, Longnecker DS, Luttges J, Maitra A, Offerhaus GJ, Pérez-Gallego L, Redston M and Tuveson DA: Pathology of genetically engineered mouse models of pancreatic exocrine cancer: consensus report and recommendations. Cancer Res 66(1): 95-106, 2006. PMID: 16397221. DOI: 10.1158/00085472.CAN-05-2168

8 Lomberk G, Dusetti N, Iovanna J and Urrutia R: Emerging epigenomic landscapes of pancreatic cancer in the era of precision medicine. Nat Commun 10(1): 3875, 2019. PMID: 31462645. DOI: 10.1038/s41467-019-11812-7

9 Yamamoto K, Tateishi K, Kudo Y, Sato T, Yamamoto S, Miyabayashi K, Matsusaka K, Asaoka Y, Ijichi H, Hirata Y, Otsuka M, Nakai Y, Isayama H, Ikenoue T, Kurokawa M, Fukayama M, Kokudo N, Omata M and Koike K: Loss of histone demethylase KDM6B enhances aggressiveness of pancreatic cancer through downregulation of $\mathrm{C} / \mathrm{EBP} \alpha$. Carcinogenesis 35(11): 2404-2414, 2014. PMID: 24947179. DOI: $10.1093 /$ carcin/bgu136

10 Mallen-St Clair J, Soydaner-Azeloglu R, Lee KE, Taylor L, Livanos A, Pylayeva-Gupta Y, Miller G, Margueron R, Reinberg D and Bar-Sagi D: EZH2 couples pancreatic regeneration to neoplastic progression. Genes Dev 26(5): 439-444, 2012. PMID: 22391448. DOI: $10.1101 /$ gad.181800.111

11 Tzatsos A, Paskaleva P, Ferrari F, Deshpande V, Stoykova S, Contino G, Wong KK, Lan F, Trojer P, Park PJ and Bardeesy N: KDM2B promotes pancreatic cancer via Polycomb-dependent and -independent transcriptional programs. J Clin Invest 123(2): 727-739, 2013. PMID: 23321669. DOI: 10.1172/JCI64535

12 Kimura Y, Fukuda A, Ogawa S, Maruno T, Takada Y, Tsuda M, Hiramatsu Y, Araki O, Nagao M, Yoshikawa T, Ikuta K, Yoshioka T, Wang Z, Akiyama H, Wright CV, Takaori K, 
Uemoto S, Chiba $\mathrm{T}$ and Seno H: ARID1A maintains differentiation of pancreatic ductal cells and inhibits development of pancreatic ductal adenocarcinoma in mice. Gastroenterology 155(1): 194-209, 2018. PMID: 29604291. DOI: $10.1053 /$ j.gastro.2018.03.039

13 Tsuda M, Fukuda A, Roy N, Hiramatsu Y, Leonhardt L, Kakiuchi N, Hoyer K, Ogawa S, Goto N, Ikuta K, Kimura Y, Matsumoto Y, Takada Y, Yoshioka T, Maruno T, Yamaga Y, Kim GE, Akiyama H, Ogawa S, Wright CV, Saur D, Takaori K, Uemoto S, Hebrok M, Chiba T and Seno H: The BRG1/SOX9 axis is critical for acinar cell-derived pancreatic tumorigenesis. J Clin Invest 128(8): 3475-3489, 2018. PMID: 30010625. DOI: 10.1172/JCI94287

14 Shinkai Y and Tachibana M: H3K9 methyltransferase G9a and the related molecule GLP. Genes Dev 25(8): 781-788, 2011. PMID: 21498567. DOI: 10.1101/gad.2027411

15 Pan MR, Hsu MC, Luo CW, Chen LT, Shan YS and Hung WC: The histone methyltransferase G9a as a therapeutic target to override gemcitabine resistance in pancreatic cancer. Oncotarget 7(38): 61136-61151, 2016. PMID: 27531902. DOI: 10.18632/oncotarget.11256

16 Yuan Y, Tang AJ, Castoreno AB, Kuo SY, Wang Q, Kuballa P, Xavier R, Shamji AF, Schreiber SL and Wagner BK: Gossypol and an HMT G9a inhibitor act in synergy to induce cell death in pancreatic cancer cells. Cell Death Dis 4(6): e690, 2013. PMID: 23807219. DOI: 10.1038/cddis.2013.191

17 Yuan Y, Wang Q, Paulk J, Kubicek S, Kemp MM, Adams DJ, Shamji AF, Wagner BK and Schreiber SL: A small-molecule probe of the histone methyltransferase G9a induces cellular senescence in pancreatic adenocarcinoma. ACS Chem Biol 7(7): 1152-1157, 2012. PMID: 22536950. DOI: 10.1021/cb300139y

18 Boj SF, Hwang CI, Baker LA, Chio II, Engle DD, Corbo V, Jager M, Ponz-Sarvise M, Tiriac H, Spector MS, Gracanin A, Oni T, Yu KH, van Boxtel R, Huch M, Rivera KD, Wilson JP, Feigin ME, Öhlund D, Handly-Santana A, Ardito-Abraham CM, Ludwig M, Elyada E, Alagesan B, Biffi G, Yordanov GN, Delcuze B, Creighton B, Wright K, Park Y, Morsink FH, Molenaar IQ, Borel Rinkes IH, Cuppen E, Hao Y, Jin Y, Nijman IJ, Iacobuzio-Donahue C, Leach SD, Pappin DJ, Hammell M, Klimstra DS, Basturk O, Hruban RH, Offerhaus GJ, Vries RG, Clevers $\mathrm{H}$ and Tuveson DA: Organoid models of human and mouse ductal pancreatic cancer. Cell 160(1-2): 324-338, 2015. PMID: 25557080. DOI: 10.1016/j.cell.2014.12.021

19 Tiriac H, Belleau P, Engle DD, Plenker D, Deschênes A, Somerville TDD, Froeling FEM, Burkhart RA, Denroche RE, Jang GH, Miyabayashi K, Young CM, Patel H, Ma M, LaComb JF, Palmaira RLD, Javed AA, Huynh JC, Johnson M, Arora K, Robine N, Shah M, Sanghvi R, Goetz AB, Lowder CY, Martello L, Driehuis E, LeComte N, Askan G, Iacobuzio-Donahue CA, Clevers H, Wood LD, Hruban RH, Thompson E, Aguirre AJ, Wolpin BM, Sasson A, Kim J, Wu M, Bucobo JC, Allen P, Sejpal DV, Nealon W, Sullivan JD, Winter JM, Gimotty PA, Grem JL, DiMaio DJ, Buscaglia JM, Grandgenett PM, Brody JR, Hollingsworth MA, O'Kane GM, Notta F, Kim E, Crawford JM, Devoe C, Ocean A, Wolfgang CL, Yu KH, Li E, Vakoc CR, Hubert B, Fischer SE, Wilson JM, Moffitt R, Knox J, Krasnitz A, Gallinger S and Tuveson DA: Organoid profiling identifies common responders to chemotherapy in pancreatic cancer. Cancer Discov 8(9): 1112-1129, 2018. PMID: 29853643. DOI: 10.1158/2159-8290.CD-18-0349
20 Seino T, Kawasaki S, Shimokawa M, Tamagawa H, Toshimitsu K, Fujii M, Ohta Y, Matano M, Nanki K, Kawasaki K, Takahashi S, Sugimoto S, Iwasaki E, Takagi J, Itoi T, Kitago M, Kitagawa $\mathrm{Y}$, Kanai $\mathrm{T}$ and Sato T: Human pancreatic tumor organoids reveal loss of stem cell niche factor dependence during disease progression. Cell Stem Cell 22(3): 454-467, 2018. PMID: 29337182. DOI: $10.1016 /$ j.stem.2017.12.009

21 Tachibana M, Sugimoto K, Nozaki M, Ueda J, Ohta T, Ohki M, Fukuda M, Takeda N, Niida H, Kato H and Shinkai Y: G9a histone methyltransferase plays a dominant role in euchromatic histone $\mathrm{H} 3$ lysine 9 methylation and is essential for early embryogenesis. Genes Dev 16(14): 1779-1791, 2002. PMID: 12130538. DOI: $10.1101 / \operatorname{gad} .989402$

22 Kawaguchi Y, Cooper B, Gannon M, Ray M, MacDonald RJ and Wright CV: The role of the transcriptional regulator Ptf1a in converting intestinal to pancreatic progenitors. Nat Genet 32(1): 128-134, 2002. PMID: 12185368. DOI: 10.1038/ng959

23 Jackson EL, Willis N, Mercer K, Bronson RT, Crowley D, Montoya R, Jacks T and Tuveson DA: Analysis of lung tumor initiation and progression using conditional expression of oncogenic K-ras. Genes Dev 15(24): 3243-3248, 2001. PMID: 11751630. DOI: $10.1101 /$ gad 943001

24 Hruban RH, Adsay NV, Albores-Saavedra J, Compton C, Garrett ES, Goodman SN, Kern SE, Klimstra DS, Klöppel G, Longnecker DS, Lüttges $J$ and Offerhaus GJ: Pancreatic intraepithelial neoplasia: a new nomenclature and classification system for pancreatic duct lesions. Am J Surg Pathol 25(5): 579-586, 2001. PMID: 11342768. DOI: 10.1097/00000478-200105000-00003

25 Buenrostro JD, Giresi PG, Zaba LC, Chang HY and Greenleaf WJ: Transposition of native chromatin for fast and sensitive epigenomic profiling of open chromatin, DNA-binding proteins and nucleosome position. Nat Methods 10(12): 1213-1218, 2013. PMID: 24097267. DOI: $10.1038 /$ nmeth.2688

$26 \mathrm{Li} \mathrm{H}$ and Durbin R: Fast and accurate short read alignment with Burrows-Wheeler transform. Bioinformatics 25(14): 1754-1760, 2009. PMID: 19451168. DOI: 10.1093/bioinformatics/btp324

27 Zhang Y, Liu T, Meyer CA, Eeckhoute J, Johnson DS, Bernstein BE, Nusbaum C, Myers RM, Brown M, Li W and Liu XS: Model-based analysis of ChIP-Seq (MACS). Genome Biol 9(9): R137, 2008. PMID: 18798982. DOI: 10.1186/gb-2008-9-9-r137

28 Liao Y, Smyth GK and Shi W: featureCounts: an efficient general purpose program for assigning sequence reads to genomic features. Bioinformatics 30(7): 923-930, 2014. PMID: 24227677. DOI: 10.1093/bioinformatics/btt656

29 Robinson MD, McCarthy DJ and Smyth GK: edgeR: a Bioconductor package for differential expression analysis of digital gene expression data. Bioinformatics 26(1): 139-140, 2010. PMID: 19910308. DOI: 10.1093/bioinformatics/btp616

30 McLean CY, Bristor D, Hiller M, Clarke SL, Schaar BT, Lowe $\mathrm{CB}$, Wenger $\mathrm{AM}$ and Bejerano G: GREAT improves functional interpretation of cis-regulatory regions. Nat Biotechnol 28(5): 495-501, 2010. PMID: 20436461. DOI: 10.1038/nbt.1630

31 Bailey JM, Alsina J, Rasheed ZA, McAllister FM, Fu YY, Plentz R, Zhang H, Pasricha PJ, Bardeesy N, Matsui W, Maitra A and Leach SD: DCLK1 marks a morphologically distinct subpopulation of cells with stem cell properties in preinvasive pancreatic cancer. Gastroenterology 146(1): 245-256, 2014. PMID: 24096005. DOI: 10.1053/j.gastro.2013.09.050

32. Westphalen CB, Takemoto Y, Tanaka T, Macchini M, Jiang Z, Renz BW, Chen X, Ormanns S, Nagar K, Tailor Y, May R, Cho 
Y, Asfaha S, Worthley DL, Hayakawa Y, Urbanska AM, Quante M, Reichert M, Broyde J, Subramaniam PS, Remotti H, Su GH, Rustgi AK, Friedman RA, Honig B, Califano A, Houchen CW, Olive KP and Wang TC: Dclk1 defines quiescent pancreatic progenitors that promote injury-induced regeneration and tumorigenesis. Cell Stem Cell 18(4): 441-455, 2016. PMID: 27058937. DOI: $10.1016 /$ j.stem.2016.03.016

33 May R, Sureban SM, Lightfoot SA, Hoskins AB, Brackett DJ, Postier RG, Ramanujam R, Rao CV, Wyche JH, Anant S and Houchen CW: Identification of a novel putative pancreatic stem/progenitor cell marker DCAMKL-1 in normal mouse pancreas. Am J Physiol Gastrointest Liver Physiol 299(2): G303310, 2010. PMID: 20522640. DOI: 10.1152/ajpgi.00146.2010

34 Delgiorno KE, Hall JC, Takeuchi KK, Pan FC, Halbrook CJ, Washington MK, Olive KP, Spence JR, Sipos B, Wright CV, Wells JM and Crawford HC: Identification and manipulation of biliary metaplasia in pancreatic tumors. Gastroenterology 146(1): 233-244, 2014. PMID: 23999170. DOI: 10.1053/j.gastro. 2013.08.053

35 Qiu W, Remotti HE, Tang SM, Wang E, Dobberteen L, Lee Youssof A, Lee JH, Cheung EC and Su GH: Pancreatic DCLK1 ${ }^{+}$ cells originate distinctly from $\mathrm{PDX} 1^{+}$progenitors and contribute to the initiation of intraductal papillary mucinous neoplasm in mice. Cancer Lett 423: 71-79, 2018. PMID: 29526803. DOI: 10.1016/j.canlet.2018.03.009

36 Collins MA, Yan W, Sebolt-Leopold JS and Pasca di Magliano M: MAPK signaling is required for dedifferentiation of acinar cells and development of pancreatic intraepithelial neoplasia in mice. Gastroenterology 146(3): 822-834, 2014. PMID: 24315826. DOI: 10.1053/j.gastro.2013.11.052

37 Hermann PC, Sancho P, Cañamero M, Martinelli P, Madriles F, Michl P, Gress T, de Pascual R, Gandia L, Guerra C, Barbacid M, Wagner M, Vieira CR, Aicher A, Real FX, Sainz B Jr and Heeschen $\mathrm{C}$ : Nicotine promotes initiation and progression of KRAS-induced pancreatic cancer via Gata6-dependent dedifferentiation of acinar cells in mice. Gastroenterology 147(5): 1119-1133, 2014. PMID: 25127677. DOI: $10.1053 /$ j.gastro.2014.08.002

38 Avgustinova A, Symeonidi A, Castellanos A, Urdiroz-Urricelqui U, Solé-Boldo L, Martín M, Pérez-Rodríguez I, Prats N, Lehner B, Supek F and Benitah SA: Loss of G9a preserves mutation patterns but increases chromatin accessibility, genomic instability and aggressiveness in skin tumours. Nat Cell Biol 20(12): 14001409, 2018. PMID: 30455462. DOI: 10.1038/s41556-018-0233-x

39 Mumby MC and Walter G: Protein serine/threonine phosphatases: structure, regulation, and functions in cell growth. Physiol Rev 73(4): 673-699, 1993. PMID: 8415923. DOI: 10.1152/physrev. 1993.73.4.673

40 Sangodkar J, Perl A, Tohme R, Kiselar J, Kastrinsky DB, Zaware N, Izadmehr S, Mazhar S, Wiredja DD, O'Connor CM, Hoon D, Dhawan NS, Schlatzer D, Yao S, Leonard D, Borczuk AC, Gokulrangan G, Wang L, Svenson E, Farrington CC, Yuan E, Avelar RA, Stachnik A, Smith B, Gidwani V, Giannini HM, McQuaid D, McClinch K, Wang Z, Levine AC, Sears RC, Chen
EY, Duan Q, Datt M, Haider S, Ma'ayan A, DiFeo A, Sharma N, Galsky MD, Brautigan DL, Ioannou YA, Xu W, Chance MR, Ohlmeyer M and Narla G: Activation of tumor suppressor protein PP2A inhibits KRAS-driven tumor growth. J Clin Invest 127(6): 2081-2090, 2017. PMID: 28504649. DOI: 10.1172/JCI89548

41 Neuzillet C, Hammel P, Tijeras-Raballand A, Couvelard A and Raymond E: Targeting the Ras-ERK pathway in pancreatic adenocarcinoma. Cancer Metastasis Rev 32(1-2): 147-162, 2013. PMID: 23085856. DOI:10.1007/s10555-012-9396-2

42 Shimaji K, Konishi T, Yoshida H, Kimura H and Yamaguchi M: Genome-wide genetic screen identified the link between dG9a and epidermal growth factor receptor signaling pathway in vivo. Exp Cell Res 346(1): 53-64, 2016. PMID: 27343629. DOI: 10.1016/j.yexcr.2016.06.013

$43 \mathrm{Li} \mathrm{KC}$, Hua KT, Lin YS, Su CY, Ko JY, Hsiao M, Kuo ML and Tan CT: Inhibition of G9a induces DUSP4-dependent autophagic cell death in head and neck squamous cell carcinoma. Mol Cancer 13: 172, 2014. PMID: 25027955. DOI: 10.1186/1476-4598-13-172

44 Schones DE, Chen X, Trac C, Setten R and Paddison PJ: G9a/GLP-dependent H3K9me2 patterning alters chromatin structure at $\mathrm{CpG}$ islands in hematopoietic progenitors. Epigenetics Chromatin 7: 23, 2014. PMID: 25237399. DOI: 10.1186/1756-8935-7-23

45 Luo CW, Wang JY, Hung WC, Peng G, Tsai YL, Chang TM, Chai CY, Lin CH and Pan MR: G9a governs colon cancer stem cell phenotype and chemoradioresistance through PP2A-RPA axis-mediated DNA damage response. Radiother Oncol 124(3): 395-402, 2017. PMID: 28351524. DOI: 10.1016/j.radonc. 2017.03.002

46 Klose RJ, Kallin EM and Zhang Y: JmjC-domain-containing proteins and histone demethylation. Nat Rev Genet 7(9): 715727, 2006. PMID: 16983801. DOI: $10.1038 / \mathrm{nrg} 1945$

47 Dandawate P, Ghosh C, Palaniyandi K, Paul S, Rawal S, Pradhan R, Sayed AAA, Choudhury S, Standing D, Subramaniam D, Padhye SB, Gunewardena S, Thomas SM, Neil MO, Tawfik O, Welch DR, Jensen RA, Maliski S, Weir S, Iwakuma T, Anant $\mathrm{S}$ and Dhar A: The histone demethylase KDM3A, increased in human pancreatic tumors, regulates expression of DCLK1 and promotes tumorigenesis in mice. Gastroenterology 157(6): 1646-1659, 2019. PMID: 31442435. DOI: $10.1053 /$ j.gastro.2019.08.018
Received August 5, 2020

Revised August 28, 2020

Accepted August 31, 2020 